\title{
Responses of $\mathrm{CHO}-\mathrm{DHFR}$ cells to ratio of asparagine to glutamine in feed media: cell growth, antibody production, metabolic waste, glutamate, and energy metabolism
}

\author{
Li-xiang Zhang ${ }^{1}$, Wei-yan Zhang ${ }^{1}$, Chen Wang ${ }^{1}$, Jin-tao Liu' ${ }^{1}$, Xian-cun Deng ${ }^{1,2}$, Xu-ping Liu' ${ }^{1}$ Li Fan* \\ and Wen-song Tan'
}

\begin{abstract}
Background: Optimization of chemically defined medium has been a critical way to produce monoclonal antibody. Usually, amount of glutamine was added into the feed medium, but a half of asparagine was added. Our study found that asparagine was important in the antibody production phase. Increasing the ratio of asparagine to glutamine in feed medium for enhancement of antibody production in CHO-DHFR cell culture would be an efficient way.

Results: We optimized the total amount and the ratio of the two vital amino acids in feed medium to increase antibody production. In this work, we have demonstrated that feeding medium of high ratio between asparagine and glutamine $(\mathrm{FB}-\mathrm{H})$ can enhance the cell density after reaching the stationary phase. Moreover, FB-H was shown to improve cell maintenance, and increased the antibody production. The metabolic flux analysis proved that ratio of asparagine to glutamine had little influence on glycolysis. Furthermore, the TCA cycle of FB-H was enhanced by $20 \%$ compared to that of low ratio of asparagine to glutamine (FB-L). And the energy metabolism of FB-H was $22.6 \%$ higher than that of FB-L. For the later, lactate can be less produced in FB-H.
\end{abstract}

Conclusions: We should improve the ratio between asparagine and glutamine in feed medium properly under the premise of no influence on cell growth to achieve high mAb producing goal.

Keywords: Chinese Hamster ovary cells, Feed medium, Ratio between asparagine and glutamine, Cell growth, Monoclonal antibody production, Metabolism

\section{Background}

Mammalian cell culture has been used to produce various recombinant proteins for therapeutic applications (Wurm 2004). CHO cell is a kind of important industrial cell line for monoclonal antibodies $(\mathrm{mAb})$ production due to its robust growth feature and the ability to produce desired post-translational modifications. Industrial scale production of recombinant therapeutic proteins, including $\mathrm{mAb}$, is predominantly performed in fed-batch

\footnotetext{
*Correspondence: fanli@ecust.edu.cn

${ }^{1}$ The State Key Laboratory of Bioreactor Engineering, East China University of Science and Technology, 130 Mei-Long Road, P. O. Box 309, Shanghai 200237, Peoples'Republic of China

Full list of author information is available at the end of the article
}

cultures (Birch and Racher 2006). Optimization of cell culture medium to meet the nutrient demands and minimize toxic production in cell cultures has played a critical role in the productivity improvements, especially for dihydrofolate reductase-deficient Chinese hamster ovary (CHO-DHFR) cells, while they were easy to accumulate metabolic wastes (Altamirano et al. 2004; Matsuoka et al. 2006; Behjousiar et al. 2012). Therefore, medium optimization is considered as one of the key contributors to high titer. To better control cell metabolism and avoid using of animal-derived raw materials and ill-defined hydrolysates, much progress has been made in understanding cell nutrient requirements and development of chemically defined medium including feed formulations 
over the last 10 years (Wurm 2004; Franek et al. 2000; Huang et al. 2010; Young 2013). More recently, metabolic flux analysis (MFA) has become a useful tool in medium development for hybridoma (Follstad et al. 1999; Europa et al. 2000; Gambhir et al. 2003) and CHO cell cultures (Nyberg et al. 1999; Altamirano et al. 2006), which can help quantifying nutrient demands and metabolite production in cell culture (Zhao et al. 2009).

Mammalian cells including $\mathrm{CHO}$ cells consume large quantities of glucose and glutamine in carbon and nitrogen metabolism, while releasing waste products lactate and ammonia. It is reported that asparagine and glutamine are significant nitrogen and energy sources. Additionally, glutamine is known as an anaplerotic metabolic fueling biosynthesis substance (Xing et al. 2011), and asparagine is essential for the synthesis of glycine, cysteine, proteins, nucleotides, and lipids in cell proliferation. Glutamine and asparagine are the two most consumed amino acids in mammalian cell culture. To achieve high-specific growth rate, cell density, and productivity, the culture should be fed with high levels of glutamine or asparagine (Wlaschin and $\mathrm{Hu}$ 2006; Jain and Kumar 2008; Lu et al. 2013; Sengupta et al. 2011). Specifically, glutamine and asparagine are mutually related to each other not only in transportation but also in metabolism (Wipf et al. 2002; Huang et al. 2007; Kobayashi et al. 2015; $\mathrm{Xu}$ et al. 2014). Glutamine and asparagine could turn into glutamate and aspartate through deamination. And glutamate can carry on deamination to form $\alpha$-ketoglutarate $(\alpha-K G)$. In addition, aspartate used $\alpha$-ketoglutarate to form oxaloacetate and glutamate through transamination. Oxaloacetate and $\alpha$-ketoglutarate could enter TCA cycle to be further metabolized. Our study found that asparagine was important in the antibody production phase. Usually the concentration of asparagine was only half of glutamine concentration in feed media. Although asparagine and glutamine are key amino acids for cell growth and mAb productivity, but there were always more glutamine than asparagine in feed media. Therefore, how to correctly supply asparagine and glutamine in feed media to achieve high mAb production becomes a critical issue.

In this study, we performed fed-batch culture with CHO-DHFR cells. First, we optimized the total amount of asparagine and glutamine in feed media to avoid the shortage of them, and we also optimized the ratio of them in feed medium to increase antibody production. Finally, we designed FB-L (60 mM Asn, $120 \mathrm{mM}$ Gln), FB-H (120 mM Asn, $60 \mathrm{mM}$ Gln), and FB-N (with no Asn and Gln) to deeply study the effects of ratio on cell growth, antibody production, metabolic wastes, and energy metabolism. Furthermore, we used MFA method to study different processes of FB-L and FB-H during the stationary phase of fed-batch culture, such as glutamate metabolism and TCA cycle.

\section{Methods}

\section{Cell line and cell culture}

A CHO-DHFR cell line expressing a chimeric antihuman CD20 monoclonal antibody was used in this study. The cells were transfected with a plasmid encoding IgG $\mathrm{mAb}$. Cells were routinely maintained in a proteinfree cell culture, which was composed of a mixture of DMEM/Ham's F12 (1:1 (v/v); Gibco) supplemented with vitamins, nucleic acids, ethanolamine, sodium selenite, ferric citrate, Pluronic F-68, etc. This basal medium contains $50 \mathrm{mM}$ glucose, $4 \mathrm{mM}$ asparagine, and $6 \mathrm{mM}$ glutamine. Furthermore, cells were routinely passaged every 2 days at a density of $0.5 \sim 1.0 \times 10^{6}$ cells $/ \mathrm{mL}$ in shake flasks in a humidified incubator maintained at $37^{\circ} \mathrm{C}$ and $5 \% \mathrm{CO}_{2}$ with shaking at $140 \mathrm{rpm}$.

For fed-batch culture, exponentially growing $\mathrm{CHO}$ cells were collected by centrifugation (1000 rpm, $5 \mathrm{~min})$ and inoculated at a density of $0.8 \sim 1.0 \times 10^{6}$ cells $/ \mathrm{mL}$ into basal medium. Fed-batch culture was carried out using shaking flasks (Corning, NY, USA) on a rotary shaker at $140 \mathrm{rpm}$, with an medium volume of $200 \mathrm{ml}$. Feed medium with different concentrations of asparagine and glutamine for cells was added $3 \%(\mathrm{v} / \mathrm{v}) /$ day after $24 \mathrm{~h}$. The culture temperature was shifted from 37 to $32{ }^{\circ} \mathrm{C}$ at day 5. Cell suspension samples were taken every day to determine cell density, antibody concentration, and other metabolites. Two independent experiments were performed.

\section{Feed media}

The feed medium contained glucose, amino acid, vitamins, Pluronic F-68, etc. This feed medium contains $500 \mathrm{mM}$ glucose. The concentration of asparagine (Asn) and glutamine (Gln) in feed medium (FM) is listed in Table 1 . First, we fixed the ratio of asparagine to glutamine at 1:1, and increased the total amount of them to find a suitable total concentration. Then, we fixed the total amount of them, and changed the proportion between asparagine and glutamine to see the effect of ratio on titer. Finally, three fed-batch cultures were performed under different conditions to see the metabolism distinction: FB-L with feed medium contained $120 \mathrm{mM}$ glutamine and $60 \mathrm{mM}$ asparagine; FB-H with feed medium contained $60 \mathrm{mM}$ glutamine and $120 \mathrm{mM}$ asparagine; and $\mathrm{FB}-\mathrm{N}$ with feed medium contained no glutamine and asparagine.

\section{Extraction of intracellular metabolites}

Metabolism was quenched by addition of $40 \mathrm{~mL}$ of cold saline water $(9 \mathrm{~g} / \mathrm{L} \mathrm{NaCl})$ to $10 \mathrm{~mL}$ cell's sample 
Table 1 The formula of feed media used in the fed-batch cultures

\begin{tabular}{cccclc}
\hline & & Asn (mM) & Gln (mM) & Asn/Gln & Asn + Gln (mM) \\
\hline Total & T1 & 0 & 0 & $/$ & 0 \\
& T2 & 30 & 30 & $1: 1$ & 60 \\
& T3 & 60 & 60 & $1: 1$ & 120 \\
& T4 & 90 & 90 & $1: 1$ & 180 \\
Proportion & T5 & 120 & 120 & $1: 1$ & 240 \\
& P1 & 180 & 0 & $/$ & 180 \\
P2 & 150 & 30 & $5: 1$ & 180 \\
& P3 & 120 & 60 & $2: 1$ & 180 \\
& P4 & 90 & 90 & $1: 1$ & 180 \\
& P5 & 60 & 120 & $1: 2$ & 180 \\
P6 & 30 & 150 & $1: 5$ & 180 \\
P7 & 0 & 180 & $/$ & 180 \\
& FB-L & 60 & 120 & $1: 2$ & 180 \\
& FB-H & 120 & 60 & $2: 1$ & 180 \\
& FB-N & 0 & 0 & $/$ & 0 \\
\hline
\end{tabular}

$\left(1 \sim 2 \times 10^{7}\right.$ cells $)$. Then, the samples were centrifuged at $2000 \mathrm{rpm}$ and $0{ }^{\circ} \mathrm{C}$ for $1 \mathrm{~min}$ and discarded the supernatant. Intracellular metabolites were extracted by addition of $1 \mathrm{~mL} 50 \%$ acetonitrile to cells, and the tubes were vortexed vigorously. After incubation on ice for $10 \mathrm{~min}$, the tubes were centrifuged at $10,000 \mathrm{rpm}$ and $0{ }^{\circ} \mathrm{C}$ for $10 \mathrm{~min}$. The supernatant was kept at $-80^{\circ} \mathrm{C}$. Before analysis, the extracted supernatants were dried at $37{ }^{\circ} \mathrm{C}$ with air using an evaporator (Reacti-Vap/reacti-Therm; Fierce, Rochford, 1L). Dried metabolites were dissolved in water and centrifuged at 10,000 rpm for $10 \mathrm{~min}$. The aqueous solution was filtered $(0.45 \mu \mathrm{m})$ for analysis by HPLC.

\section{Analytical measurements and specific metabolic rates}

Viable cell density and cell viability were determined by counting cells with a hemocytometer using the trypan blue dye exclusion method. The mAb was purified by Protein A affinity chromatography (Hi Trap Protein A HP Columns, GE), and the mAb concentration was quantified by HPLC as described previously (Chen et al. 2012). The concentrations of glucose, ammonia, and lactate were determined using test kits purchased from Nanjing Jiancheng Bioengineering Institute and Shanghai Institute of Biological products, China. The specific consumption/production rate (q) was calculated by plotting cumulative metabolites consumption versus the integral of viable cells (IVC) (Zhao et al. 2009), and fitting the plots by a liner correlation. The slopes of the corresponding straight lines were used as average specific rates. Amino acid concentrations were assayed by reversedphase HPLC (1525 Binary HPLC pump, 717plus Autosampler, 2487 Dual $\lambda$ absorbance detector, Nova-Pak C18
$4 \mu \mathrm{m} 3.9 \times 150 \mathrm{~mm}$ column, Waters) after derivatization with ACCQ-Tag kit purchased from Waters. The oxygen uptake rate (OUR) was determined through the online dynamic method (Eyer et al. 1995).

\section{Methodology of MFA}

The metabolic network of $\mathrm{CHO}$ cell is simplified as shown in Fig. 1, while the reaction in the simplified biochemical network is listed in Additional file 1: Table S1. According to the basic principle of metabolic flux analysis, the mass conservation equation of cell metabolic network was presented:

$$
\frac{\mathrm{d} x_{i}}{\mathrm{~d} t}=\sum_{j} a_{i j} \cdot f_{j}-r_{i}
$$

where $x_{i}$, mole concentration of the $i$ th metabolite $(\mathrm{mmol} / \mathrm{L}) ; t$ reaction time $(\mathrm{h}) ; a_{i j}$, the stoichiometric coefficient of the $i$ th metabolite (non-dimensional); $f_{j}$, the metabolic flux of the $j$ th reaction ( $\mathrm{mmol} \mathrm{C} /\left(10^{9}\right.$ cells $\left.\mathrm{h}\right)$ ); and $r_{i}$, the specific rate of metabolite $i(\mathrm{mmol} \mathrm{C} /$ $\left(10^{9}\right.$ cells $\left.\left.\mathrm{h}\right)\right)$. Reactions in the metabolic networks react so fast compared to the cell growth rate that intermediate metabolites in cells are in pseudo-steady state (Chen et al. 2012; Hilal-Alnaqbi et al. 2013). So, Eq. (1) was simplified to

$$
\sum_{\mathrm{j}} \mathrm{a}_{i j} \cdot \mathrm{f}_{j}=\mathrm{r}_{i}
$$

or

$$
A \times F=r,
$$

where A, $m \times n$ matrix of stoichiometry; $F, n$ dimensions vector of reaction rate; and $r, m$ dimension vector of metabolite specific rate.

This network consists of glycolysis, tricarboxylic acid cycle (TCA), and amino acid metabolic pathways (Wlaschin and Hu 2006; Dean and Reddy 2013). The stoichiometry matrix was determined according to metabolic reactions listed in Additional file 1: Table S1. The coefficients of biomass synthesis equation (F12) were determined based on typical cell amino acid composition (Bertz et al. 2013). The coefficients of glucose and glutamine were calculated from carbon and nitrogen balance, respectively. The coefficients of antibody synthesis equation (F13) were calculated from the sequence of antibody by searching the drug bank with proprietary information.

Specific rates used to solve the equation were calculated from the data in the comparable periods with similar culture environment and relatively stable cell state (day7-day9). The spontaneous decomposition of glutamine was neglected in calculation, because it was 


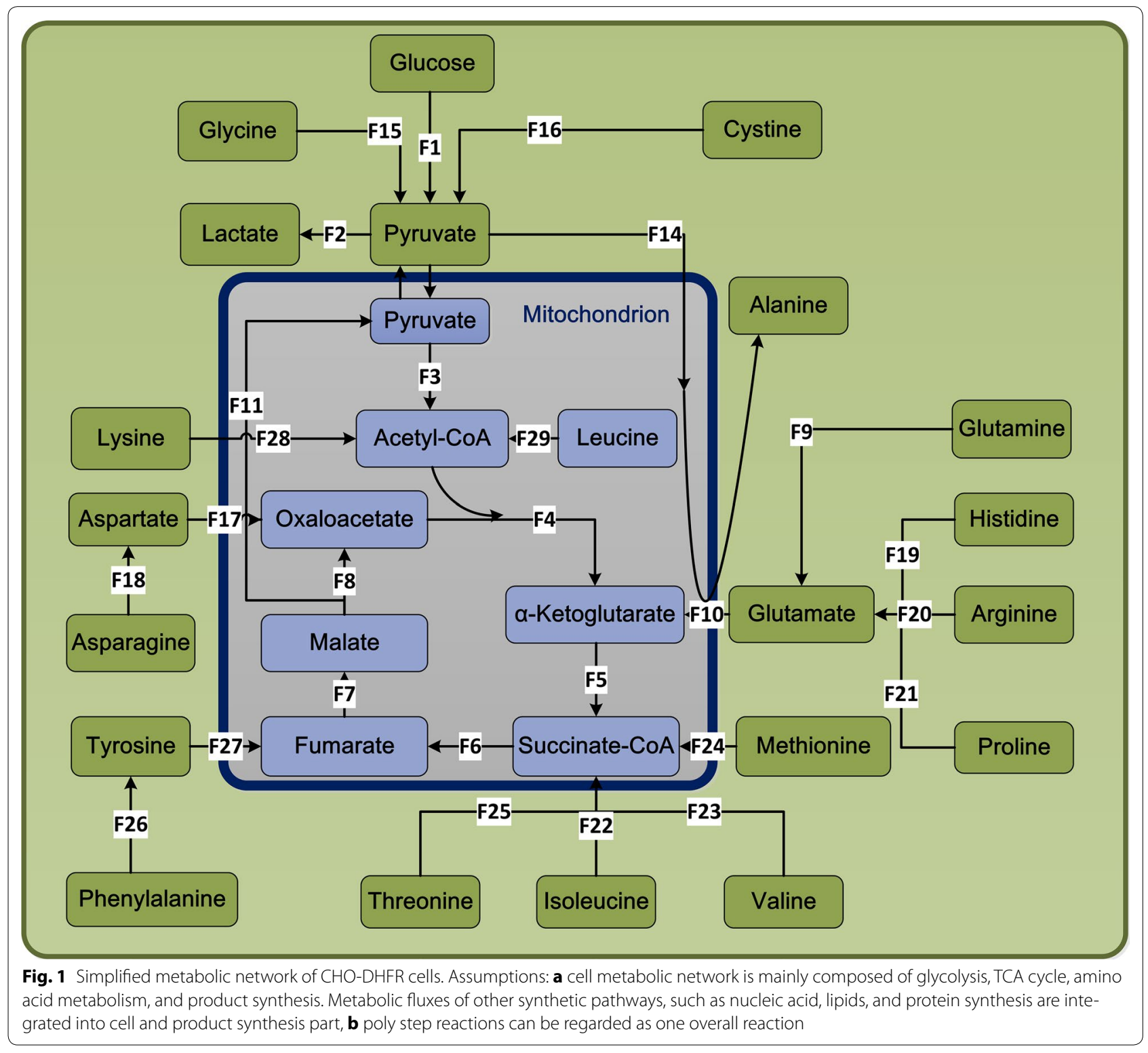

negligibly slow compared to the specific uptake rates in metabolic flux analysis. The respiratory quotient of cells was constant in metabolic flux analysis, and the value was one (Sengupta et al. 2011; Ferreira et al. 2005; Duarte et al. 2014; Ahn and Antoniewicz 2012). So, the specific rate of $\mathrm{CO}_{2}$ production was equal to that of $\mathrm{O}_{2}$ consumption. The units of all rates input were conformed to $\mathrm{mmol} /\left(10^{9}\right.$ cells day $)$.

\section{Estimation of ATP production rate}

ATP production rate was estimated according to the equation (4) (Ozturk et al. 1992)

$$
q \mathrm{ATP}=q \mathrm{Lac}+6 q \mathrm{O}_{2} .
$$

The contributions of glycolysis and oxidative phosphorylation were determined by the term $q \mathrm{Lac}$ and $6 q \mathrm{O}_{2}$, respectively.

\section{Results and discussion}

\section{The effects of glutamine and asparagine}

CHO-DHFR cells were grown in fed-batch cultures over a period of 12 days. First, we fixed the ratio of asparagine to glutamine at 1:1 and increased the total amount of them to find a suitable concentration (Table 1). Thus, the effect of ratio would not impact by the limitation of them either. Figure 2a shows the total amount profiles of antibody production and concentrations of lactate and ammonia. The antibody titer increased from 
$0.51 \mathrm{~g} / \mathrm{L}$ with no asparagine and glutamine to $0.95 \mathrm{~g} / \mathrm{L}$ with $90 \mathrm{mM}$ asparagine and $90 \mathrm{mM}$ glutamine. When the total amount increased from $180 \mathrm{mM}$ to $240 \mathrm{mM}$, the $\mathrm{mAb}$ titer was not increased significantly. But the concentration of lactate and ammonia was increased following the addition of total amount. Thus, we chose the total amount at $180 \mathrm{mM}$. Then, we fixed the total amount $(180 \mathrm{mM})$ and changed the ratio.

Figure $2 \mathrm{~b}$ shows the ratio profiles of antibody production and concentrations of lactate and ammonia. Antibody titer slightly increased from $0.91 \mathrm{~g} / \mathrm{L}(180 \mathrm{mM}$ Asn, $0 \mathrm{mM}$ Gln) to $1.11 \mathrm{~g} / \mathrm{L}$ (120 mM Asn, $60 \mathrm{mM} \mathrm{Gln}$ ), which then rapidly decreased to $0.62 \mathrm{~g} / \mathrm{L}$ (0 mM Asn, $180 \mathrm{mM}$ $\mathrm{Gln})$. The concentration of ammonia was changeless during the ratio of gradient. But the lactate concentration was increased following the addition glutamine concentration. Thus, we chose high ratio (Asn:Gln $=2: 1$, named FB-H), low ratio (Asn:Gln = 1:2, named FB-L), and no asparagine and glutamine (FB-N) in feed medium to study the effects of ratio on cell growth, antibody production, and metabolism deeply.

The time profiles of cell growth are shown in Additional file 2: Fig. S1. There were differences between them, but they had no statistical significance. The differences of antibody titer were due to the productivity of a single cell. And the metabolic profiles were affected by changes in nutrient supplements.

\section{The impacts of ratio between asparagine and glutamine on cell growth and antibody production}

The results of fed-batch culture in shaking flasks of three fed-batch cultures were summarized. Figure $3 a$ and $b$ show the time profiles of viable cell density and viability in the fed-batch cultures. Due to the concentrations of asparagine and glutamine were optimized, the cells directly entered the logarithmic growth phase without delay. FB-H reached maximum viable cell density of $3.92 \times 10^{6}$ cells $/ \mathrm{mL}$ at day 6 , while FB-L was $3.32 \times 10^{6}$ cells $/ \mathrm{mL}$ and $\mathrm{FB}-\mathrm{N}$ was $3.43 \times 10^{6}$ cells $/ \mathrm{mL}$ at day5. Maximum VCD of FB-H was $18.0 \%$ higher than that of FB-L (or FB-N). The VCD and viability of FB-L and FB-N declined quickly from day 9 to day 12 . Interestingly, the viability and cell density of $\mathrm{FB}-\mathrm{H}$ maintained relatively higher than that in FB-L and FB-N.

Antibody production was evaluated by volumetric concentration and $\mathrm{q}_{\mathrm{mAb}}$. As shown in Fig. 3c, the mAb concentrations increased gradually during the whole fed-batch process for three cultures. The mAb concentration reached $0.791 \mathrm{~g} / \mathrm{L}$ (FB-L), $1.056 \mathrm{~g} / \mathrm{L}(\mathrm{FB}-\mathrm{H})$, and $0.589 \mathrm{~g} / \mathrm{L}(\mathrm{FB}-\mathrm{N})$ at day 12, respectively. Antibody production in FB-H was 33.5 and 79.3 \% higher compared to FB-L and FB-N. We found that antibody production was improved by increasing the ratio between asparagine and glutamine. By plotting cumulative mAb concentration versus viable cell density (IVCC), $\mathrm{q}_{\mathrm{mAb}}$ was determined, which denoted a single cell's ability to produce antibody. As shown in Fig. 3d, the $\mathrm{q}_{\mathrm{mAb}}$ of FB-H was $20 \%$ higher than that of FB-L and $84.6 \%$ higher than that of FB-N. We found that the enhancement of antibody production in FB-H was due to increase of VCD and $\mathrm{q}_{\mathrm{mAb}}$. However, the higher titer of FB-L than that of FB-N was due to the increase of a single cell's ability to produce antibody.

\section{Effects of ratio on metabolic wastes and energy sources}

The lactate, ammonia, and alanine concentrations changed greatly among metabolites in the fed-batch cultures. Three metabolites were produced rather than consumed. Both lactate and ammonia were metabolic wastes, which was harmful for cell culture. They were stern problems need to be solved because CHO-DHFR cells were easy to accumulated metabolic wastes. The generated lactate of FB-H was approximately $19.1 \%$ lower than that of FB-L during the stationary phase, while both of them were higher than FB-N obviously (Fig. 3e). As for the generated ammonia, there was no evident difference between FB- $\mathrm{L}$ and $\mathrm{FB}-\mathrm{H}$, and it maintained low concentration in FB-N, which was $40 \%$ lower than that of FN-L and FB-H after day 7 (Fig. 3f). We got the same conclusion about the alanine concentration (Fig. 3g). As previously mentioned, the by-product ammonia was related to the total amount of asparagine and glutamine, but the concentration of lactate was only related to the amount of glutamine (Fig. 2a and b).

The time profile of glutamine concentration is shown in Fig. 3h. The concentration of glutamine decreased during the exponential growth phase from day 0 to day 3 , and remained relatively constant during the next 4 days. But then they rapidly increased from day 8 to day 12 . Thus, glutamine consumed fleetly during exponential growth phase and accumulated during antibody production phase (day 7 day 12). And the concentration of glutamine in FB-L (120 mM Asn, $60 \mathrm{mM} \mathrm{Gln}$ ) was approximately $37.5 \%(1.80 \mathrm{mM})$ higher than that of FB-H (60 mM Asn, $120 \mathrm{mM}$ Gln) during the antibody production phase. The time profile of asparagine concentration is shown in Fig. 3i. The concentration of asparagine decreased during the exponential growth phase, and remained relatively constant from day 6 to 12 . Asparagine concentration of FB-H was slightly (approximately $7 \%$ ) higher than that of FB-L. Thus, asparagine was consumed rapidly during antibody production phase.

The time profiles of glutamate and aspartate concentration are shown in Fig. $3 j$ and k. Glutamate concentration was changeless among three cultures during the whole process. This kind of metabolite was always the key metabolism. So, we should study its metabolism deeply. 

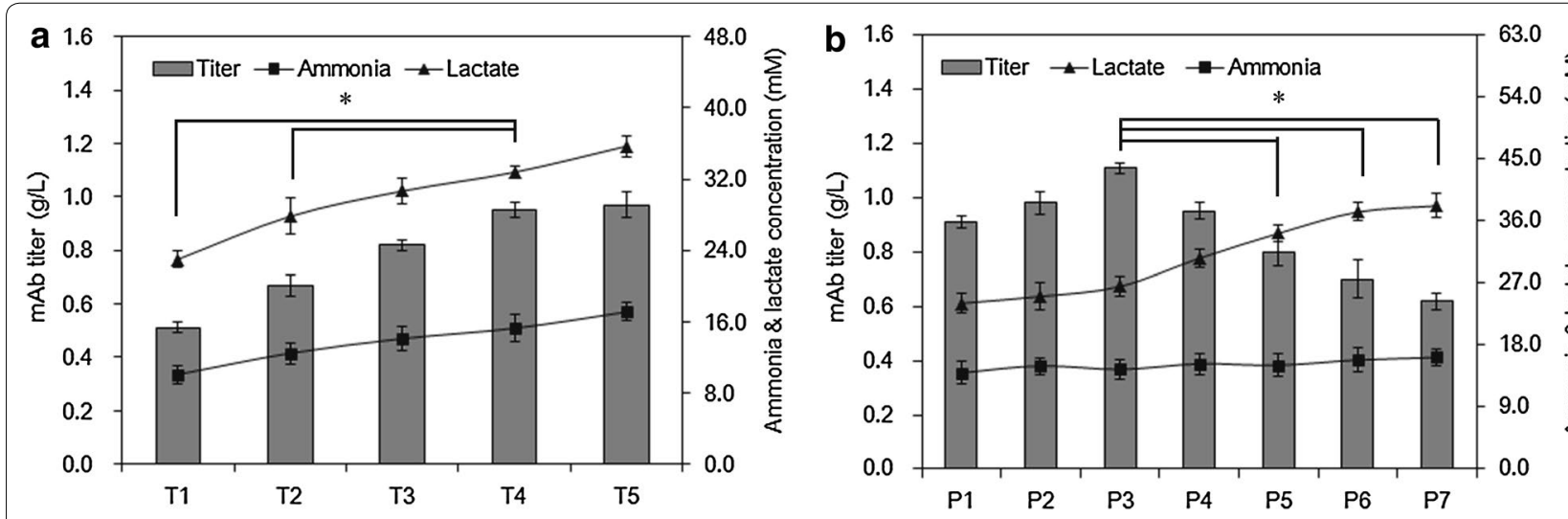

Fig. 2 Effects of asparagine and glutamine on titer and metabolic wastes. Results of total amount of asparagine and glutamine (a) and ratio of asparagine to glutamine $(\mathbf{b})$ in feed media were listed. Significant analysis of (a) was titer, lactate, and ammonia. Significant analysis of (b) was titer and lactate $\left({ }^{*} p<0.05\right)$

Aspartate concentration of FB-N remained unchanged, while that of FB-L and FB-H increased. Aspartate concentration of $\mathrm{FB}-\mathrm{H}$ was approximately $26.7 \%$ higher than that of FB-L during antibody production phase. As shown in Fig. 3l, glucose concentrations of three cultures were almost the same before day 6 . And then that of FB-N was the highest, which was approximately $13.1 \%$ and $9.5 \%$ higher than that of FB-L and FB-H. Glucose of FB-H consumed maximum.

The time profiles of Asn/Gln and Asp/Glu ratio in fermentation broths are shown in Fig. $3 \mathrm{~m}$ and $\mathrm{n}$. Ratio of Asn/Gln was decreased during the whole process. And Asn/Gln ratio in FB-H was approximately $93.4 \%$ higher than that of FB-L from day 3 to day 12. The ratio of Asp/ Glu maintained 1.30 and 1.00 in FB-H and FB-L, respectively, after day 3. Asp/Glu ratio of FB-H was $30.0 \%$ higher than that of FB-L.

\section{Metabolic kinetics analysis}

FB-H culture could improve the antibody production. To further investigate metabolism in the three cultures, we used kinetics to evaluate the impact of glutamine and asparagine on metabolism. Kinetic results of main nutrients and metabolites at different conditions from day 7 to day 9 are listed in Additional file 1: Table S2 and Fig. 4a.

As shown in Fig. 4a, the specific glucose consumption rate had no significant difference in different cultures. It meant that glucose metabolism (glycolysis pathway) was not influenced by asparagine to glutamine ratio. The lactate yield from glucose was $0.158,-0.184$, and -0.114 $(\mathrm{mmol} / \mathrm{mmol})$ for FB-L, FB-H, and FB-N, respectively. It meant that most of glucose flew into TCA cycle to provide immediate metabolites and energy in stationary phase. FB-L produced lactate, while FB-H and FB-N consumed in antibody production phase.
In Additional file 1: Table S2, all essential amino acids were in the condition of consumption. Besides, there was no evident difference. For non-essential amino acid, the differences were emerged. As reported before (Matsuoka et al. 2006), glutamine and asparagine trended toward glutamate and aspartate through deamination pathways. Aspartate used $\alpha$-ketoglutarate to produce glutamate and oxaloacetate through transamination pathways. In Additional file 1: Table S2, it showed that the specific consumption rate of aspartate in FB-H was 2.22 times of that in FB-L, but the kinetic rate of glutamate was similar between FB-L and FB-H. These data indicated that when there was a large sum of asparagine in $\mathrm{FB}-\mathrm{H}$, it could turn into aspartate through deamination pathway. Hence, the consumption rate of aspartate increased evidently. But both in FB-L and FB-H, the consumption rate of glutamate was always changeless. The reason may be that many amino acids could transfer to glutamate through transamination to maintain a stable value of glutamate. Thus, for amino acid metabolism, glutamate was a key substance in stationary phase. We need to focus on it in the following discussion.

\section{Glutamate metabolic flux analysis}

As one of the critical linkers and the similar glutamate specific consumption rate of $\mathrm{FB}-\mathrm{L}$ and $\mathrm{FB}-\mathrm{H}$, we investigated the glutamate metabolic flux analysis in FB-L and FB-H. The metabolic fluxes of glutamate are listed in Fig. 4b, c and Table 2. These data indicated that more aspartate turned into glutamate when the proportion was high ( $30 \%$ higher than that of FB-L). That was the reason why the consumption rate of aspartate increased evidently in FB-H (Table 2). The flux of glutamate production in FB-H was almost from aspartate transamination $(59.66 \%)$ and glutamine deamination $(38.96 \%)$ which accounted for more than 98 \% (Table 2). However, 


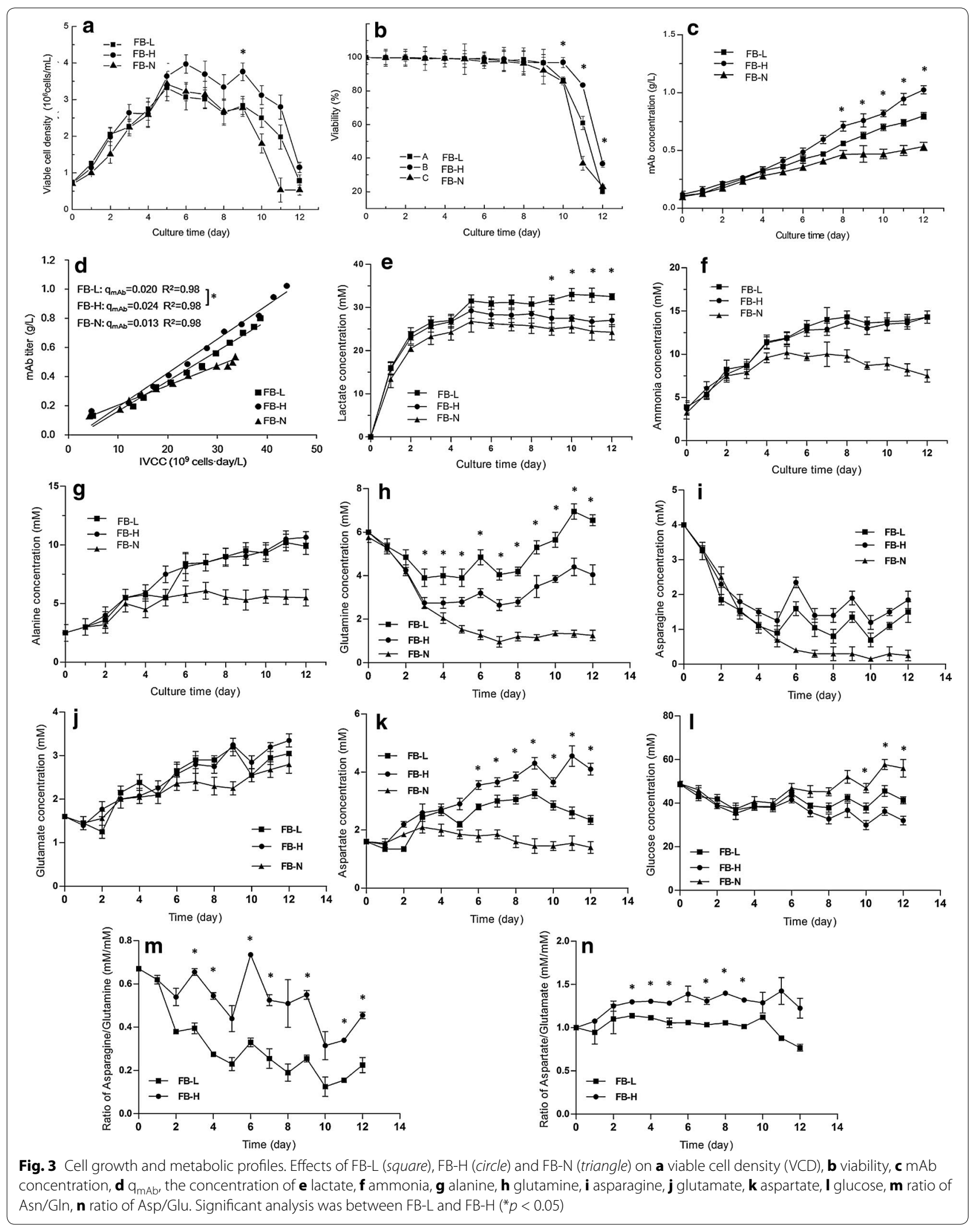




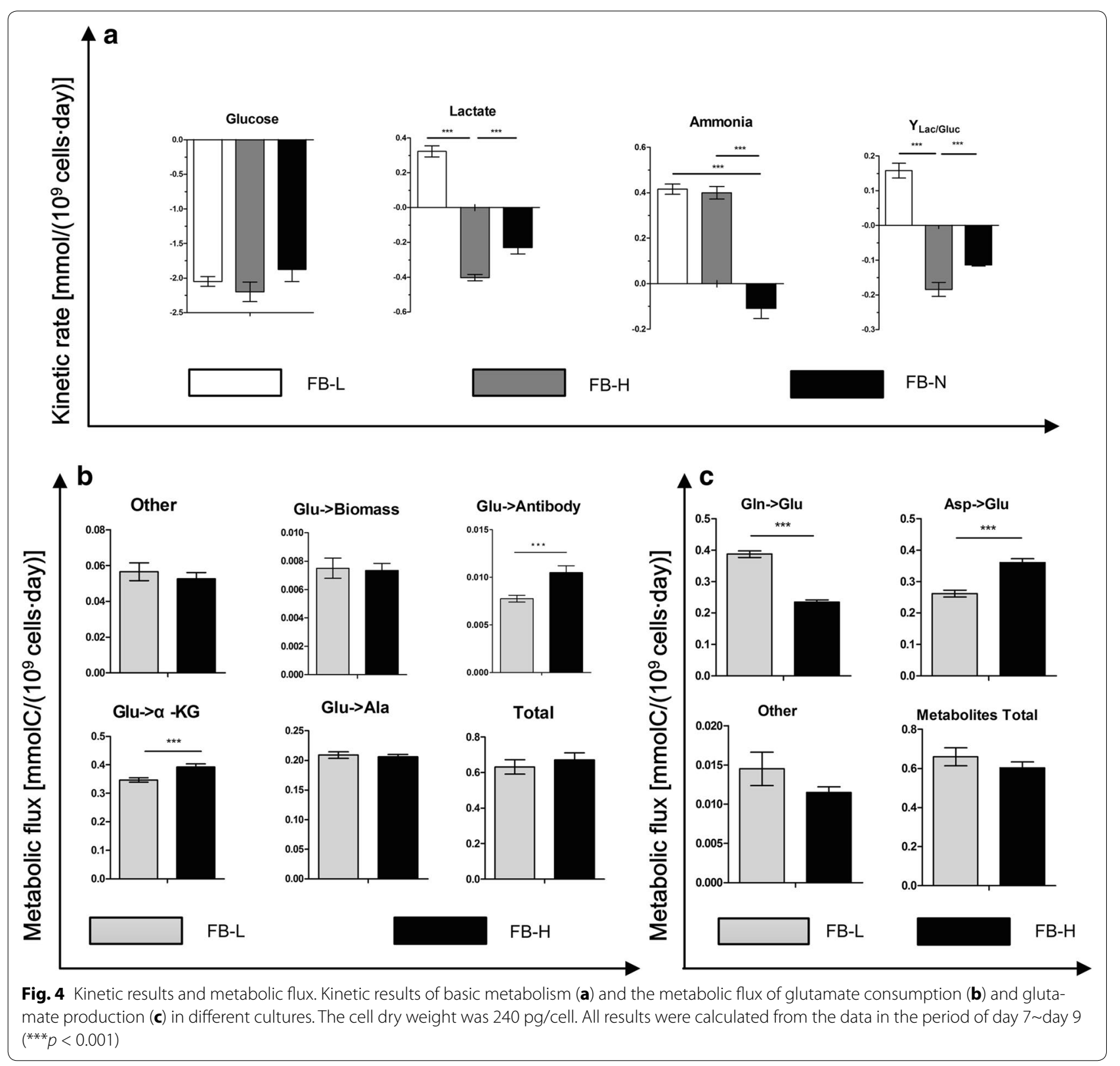

in the Fig. 4b of glutamate consumption, the flux of glutamate to $\alpha$-ketoglutarate (F10) was $0.384 \mathrm{mmol} /$ ( $10^{9}$ cells day) in FB-H which was $12.6 \%$ higher than that of FB-L. These data suggested that when there was a high ratio between asparagine and glutamine, glutamate was more inclined to produce $\alpha$-ketoglutarate which flew into TCA cycle supporting immediate metabolites and energy (Fig. 5b, c). And the flux from glutamate to alanine was reduced in FB-H. But the total fluxes of glutamate consumption were changeless. The flux of glutamate to antibody in FB-H was $35.5 \%$ higher than that of FB-L. And the flux from glutamate to biomass was similar in two cultures (Table 2).

\section{Metabolic flux distribution}

Metabolic flux distribution (FB-H/FB-L) is described in Fig. 5. The TCA cycle of FB-H was enhanced by $20 \%$ compared to FB-L (Fig. 5a). NADH and $\mathrm{FADH}_{2}$, which 
Table 2 Contribution of glutamate flow in different cultures

\begin{tabular}{llrrr}
\hline Culture & & \multicolumn{1}{l}{ FB-L } & \multicolumn{1}{l}{ FB-H } & $p$ \\
& & Percentage (\%) & Percentage (\%) & \\
\hline Glutamate & Gln-Glu & $58.73 \pm 3.02$ & $38.98 \pm 2.10$ & $* *$ \\
production & Asp-Glu & $39.26 \pm 1.25$ & $59.66 \pm 2.34$ & $* *$ \\
& Other & $2.01 \pm 0.15$ & $1.86 \pm 0.03$ & \\
& Total & $100.00 \pm 4.42$ & $100.00 \pm 4.47$ & \\
& Other & $8.65 \pm 0.11$ & $7.66 \pm 0.15$ & $* *$ \\
Glutamate & Biomass & $1.14 \pm 0.03$ & $1.07 \pm 0.07$ & \\
consumption & Antibody & $1.14 \pm 0.02$ & $1.53 \pm 0.09$ & $*$ \\
& Glu-aKG & $55.63 \pm 3.03$ & $58.81 \pm 3.25$ & \\
& Glu-Ala & $33.44 \pm 1.84$ & $31.09 \pm 2.16$ & \\
& Total & $100.00 \pm 5.03$ & $100.00 \pm 6.16$ & \\
\hline
\end{tabular}

The $p$ value was calculated between FB-L and FB-H $0.01<{ }^{*} p<0.05,0.001<{ }^{* *} p<0.01,{ }^{* * *} p<0.001$

were the products of TCA cycle, could enter the respiratory chain to form ATP. Thus, the energy production of FB-H would be raised compared to FB-L. In addition, ammonia accumulation was closely related to the total supplement of glutamine and asparagine as described before (Fig. 2a, b). Both glutamine and asparagine were firstly metabolized by deamination (Additional file 1: Table S1) which produced ammonia and then aspartate tended to occur transamination reaction (Huang et al. 2007; Duarte et al. 2014; Ahn and Antoniewicz 2012; Ozturk et al. 1992; Ahn and Antoniewicz 2012; Rajendra et al. 2012). Amino acid, such as aspartate, could use $\alpha$-ketoglutarate to initiate transamination and generate glutamate simultaneously. Under the catalytic action of glutamate dehydrogenase, glutamate occurred deamination to form $\alpha$-ketoglutarate. Thus, ammonia was related to the total supplement of glutamine and asparagine. It explained that why ammonia production was not influenced by proportion of asparagine to glutamine (Fig. 2b).

However, lactate acid metabolism was significantly influenced by the proportion of asparagine to glutamine. As shown in the metabolite flux (Fig. 5), the production fluxes of lactate and alanine in FB-H were 13.0 and $10.0 \%$ lower than that in FB-L. And lactate production was closely related to glutamine concentration (Fig. 2b). In fact, Jamey D Young has recently shown that glutamine entering TCA cycle has three possible fates: firstly, conversion to lipids; secondly, glutaminolysis to form lactate via a truncate TCA cycle; thirdly, complete oxidation to CO2 (Young 2013). In low proportion, glutamate complied with the secondly way. It could be used to supply ATP and/or NADPH with retention of carbon to form lactate (Fig. 5c). In high proportion, glutamate mostly entered the thirdly way. More glutamate could be formed from aspartate and then flowed into TCA cycle for complete oxidation to $\mathrm{CO} 2$ (Fig. 5c). Thus, the produced lactate in FB-H was approximately $19.1 \%$ lower than that in FB-L. And complete oxidation enhanced TCA cycle in FB-H.

In FB- $\mathrm{H}$, the flux of F17 (ASP $+\alpha-\mathrm{KG} \rightarrow \mathrm{OAA}+\mathrm{GLU})$ was $37.8 \%$ higher than that of FB-L. The consumption of $\alpha-\mathrm{KG}$ was fast, and the flux of F10 (GLU $\left.\rightarrow \alpha-\mathrm{KG}+\mathrm{NH}_{3}\right)$ was increased by $13.0 \%$. Thus, the fluxes of aspartate and glutamate that enter TCA cycle were enhanced, respectively. These made substances (glutamine and asparagine) use more completely (Fig. 5b). In FB-L, abundant glutamate from glutamine could not turn into other amino acids and diffused into TCA cycle. Therefore, glutamate developed into lactate through malate overflow (Fig. 5c).

\section{Energy metabolism}

Results showed that the oxygen uptake rate (OUR) increased in FB-H compared to FB-L. Compared with OUR and lactate production rate, ATP production rates are calculated and presented in Table 3 . The highest ATP production rate occurred in $\mathrm{FB}-\mathrm{H}$, which was 22.6 and $59.6 \%$ higher than that of FB-L and FB-N, respectively. And oxidative phosphorylation contribution accounted for a higher proportion in ATP production for three cultures. Considering from the aspect of energy metabolism, feed medium with high asparagine to glutamine ratio was recommended for CHO-DHFR cells.

\section{Conclusion}

In this work, we have demonstrated that feeding medium of high ratio between asparagine and glutamine can significantly enhance the cell maintenance after reaching the stationary phase. Moreover, improving the ratio between asparagine and glutamine in the feeding medium was shown to improve cell maintenance, increased the antibody production, and specific antibody production rate. Furthermore, glutamate can be formed from aspartate easily and more inclined to produce $\alpha$-ketoglutarate which flew into TCA cycle supporting immediate metabolites and energy in high proportion situation. For the 


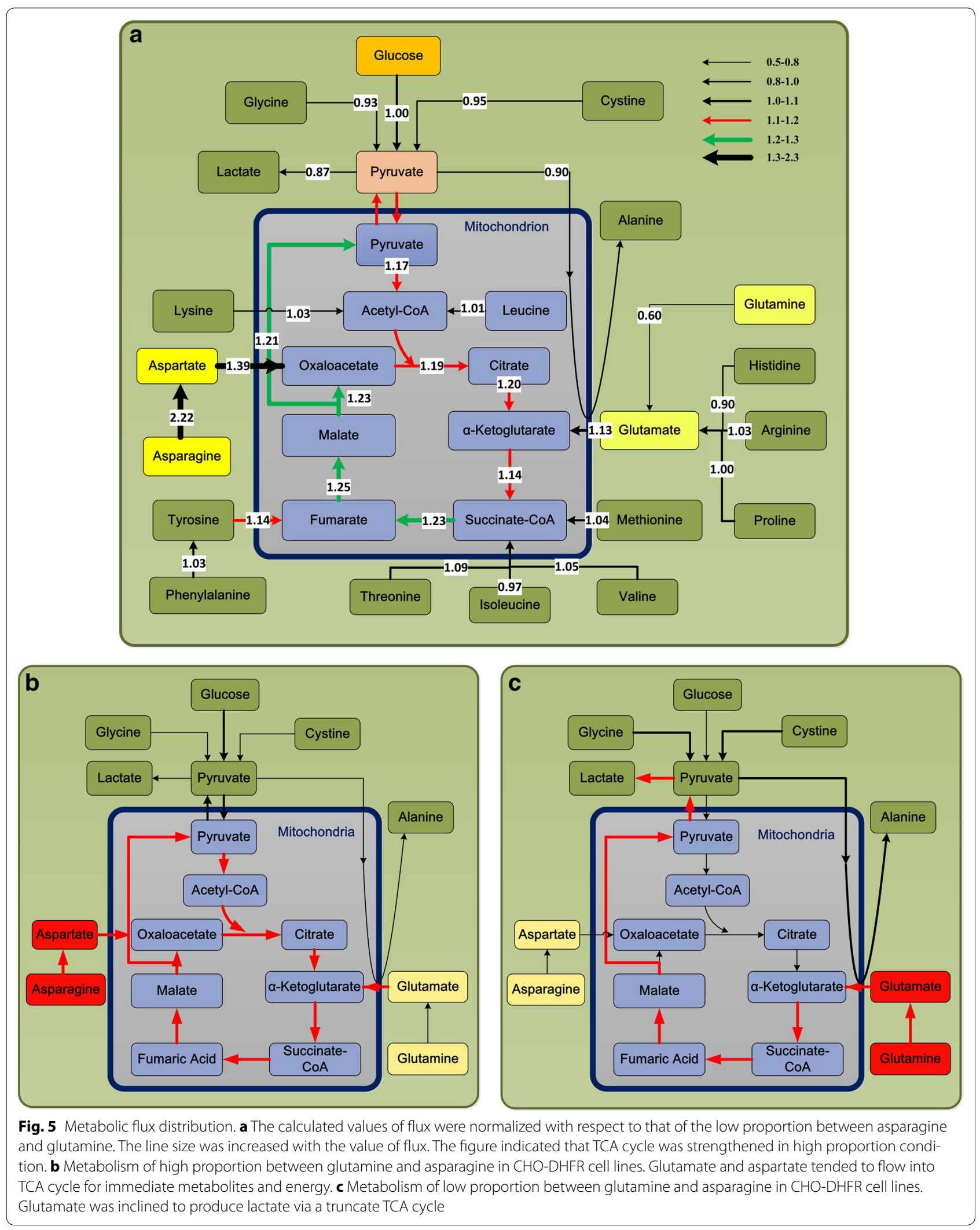


Table 3 Effect of asparagine to glutamine ratio on ATP production rate

\begin{tabular}{|c|c|c|c|}
\hline Culture & $\begin{array}{l}\text { Lactate production rate } \\
\text { (mmolC } / 10^{9} \text { cells/day) }\end{array}$ & $\begin{array}{l}\text { Oxygen consumption rate } \\
\text { (mmolc/ } / 10^{9} \text { cells/day) }\end{array}$ & $\begin{array}{l}\text { ATP production rate } \\
\text { (mmolC } / 10^{9} \text { cells } / \text { day) }\end{array}$ \\
\hline FB-L & $0.322 \pm 0.032^{* * *}$ & $4.805 \pm 0.201^{*}$ & $28.508 \pm 1.411^{*}$ \\
\hline FB-H & $-0.403 \pm 0.029$ & $5.760 \pm 0.156$ & $34.963 \pm 1.152$ \\
\hline FB-N & $-0.299 \pm 0.014$ & $3.612 \pm 0.098$ & $21.901 \pm 0.997$ \\
\hline
\end{tabular}

The $p$ value was calculated between FB-L and FB-H

$0.01<{ }^{*} p<0.05,0.001<{ }^{* *} p<0.01,{ }^{* * *} p<0.001$

later, lactate can be produced less through TCA circle in high ratio. The results of this study obviously can provide constrains and information for improving CHO-DHFR cell fed-batch culture.

\section{Additional files}

Additional file 1: Table S1. Reactions in the simplified biochemical network. Table S2. Kinetic results in different cultures.

Additional file 2: Figure S1. The time profile of cell growth. The effects of total amount (asparagine and glutamine) (A) and ratio (asparagine/ glutamine) (B) on cell growth were shown.

\section{Authors' contributions}

LXZ and WYZ conducted the experiment. LF and WST conceived the research. $\mathrm{CW}, \mathrm{JTL}, \mathrm{XPL}$, and LF have made substantive intellectual contribution to this study and substantial contributions to the design of the study. XCD provided the cell line. LXZ and LF wrote this manuscript. All authors read and approved the final manuscript.

\section{Author details}

${ }^{1}$ The State Key Laboratory of Bioreactor Engineering, East China University of Science and Technology, 130 Mei-Long Road, P. O. Box 309, Shanghai 200237, Peoples' Republic of China. ${ }^{2}$ Zhejiang Hisun Pharmaceutical (Hangzhou) Co. Ltd, Fuyang, Hangzhou, Zhejiang 311404, Peoples' Republic of China.

\section{Acknowledgements}

This work was supported by the National Natural Science Foundation of China (Nos. 21206040, 21406066), the National High Technology Research and Development Program of China (863 Program) (No. 2012AA02A303), the National Science and Technology Major Project (No.2013ZX10004003-003-003), and the Fundamental Research Funds for the Central Universities (WF1214035).

\section{Competing interests}

The authors declare that they have no competing interests.

Received: 1 September 2015 Accepted: 9 November 2015 Published online: 08 February 2016

\section{References}

Ahn WS, Antoniewicz MR (2012a) Towards dynamic metabolic flux analysis in $\mathrm{CHO}$ cell cultures. Biotechnol J 7:61-74

Ahn WS, Antoniewicz MR (2012b) Metabolic flux analysis of CHO cells in fedbatch culture. Abstr Pap Am Chem S 24:237-243

Altamirano C, Paredes C, Illanes A, Cairo JJ, Godia F (2004) Strategies for fedbatch cultivation of t-PA producing $\mathrm{CHO}$ cells: substitution of glucose and glutamine and rational design of culture medium. J Biotechnol 110:171-179

Altamirano C, Illanes A, Becerra S, Cairo JJ, Godia F (2006) Considerations on the lactate consumption by $\mathrm{CHO}$ cells in the presence of galactose. J Biotechnol 125:547-556

Behjousiar A, Kontoravdi C, Polizzi KM (2012) In Situ monitoring of intracellular glucose and glutamine in $\mathrm{CHO}$ cell culture. Public Libr of Sci One 7:29-36

Bertz M, Buchner J, Rief M (2013) Mechanical stability of the antibody domain $\mathrm{CH} 3$ homodimer in different oxidation states. J Am Chem Soc 135:15085-15091

Birch JR, Racher AJ (2006) Antibody production. Adv Drug Deliver Rev 58:671-685

Chen F, Fan L, Wang JQ, Zhou Y, Ye ZY, Zhao L, Tan WS (2012) Insight into the roles of hypoxanthine and thydimine on cultivating antibody-producing CHO cells: cell growth, antibody production and long-term stability. Appl Microbiol Biot 93:169-178

Dean J, Reddy P (2013) Metabolic analysis of antibody producing CHO cells in fed-batch production. Biotechnol Bioeng 110:1735-1747

Duarte TM, Carinhas N, Barreiro LC, Carrondo MJT, Alves PM, Teixeira AP (2014) Metabolic responses of $\mathrm{CHO}$ cells to limitation of key amino acids. Biotechnol Bioeng 111:2095-2106

Europa AF, Gambhir A, Fu PC, Hu WS (2000) Multiple steady states with distinct cellular metabolism in continuous culture of mammalian cells. Biotechnol Bioeng 67:25-34

Eyer K, Oeggerli A, Heinzle E (1995) On-line gas analysis in anomal cell cultivation: II. Methods for oxygen uptake rate estimation and its application to controlled feeding of glutamine. Biotechnol Bioeng 45:54-62

Ferreira TB, Ferreira AL, Carrondo MJT, Alves PM (2005) Two different serumfree media and osmolality effect upon human 293 cell growth and adenovirus production. Biotechnol Lett 27:1809-1813

Follstad BD, Balcarcel RR, Stephanopoulos G, Wang DIC (1999) Metabolic flux analysis of hybridoma continuous culture steady state multiplicity. Biotechnol Bioeng 63:675-683

Franek F, Hohenwarter O, Katinger H (2000) Plant protein hydrolysates: preparation of defined peptide fractions promoting growth and production in animal cells cultures. Biotechnol Prog 16:688-692

Gambhir A, Korke R, Lee JC, Fu PC, Europa A, Hu WS (2003) Analysis of cellular metabolism of hybridoma cells at distinct physiological states. J Biosci Bioeng 95:317-327

Hilal-Alnaqbi A, Hu AYC, Zhang ZB, Al-Rubeai M (2013) Growth, metabolic activity, and productivity of immobilized and freely suspended $\mathrm{CHO}$ cells in perfusion culture. Biotechnol Appl Bioc 60:436-445

Huang HY, Yu YH, Yi XP, Zhang YX (2007) Nitrogen metabolism of asparagine and glutamate in Vero cells studied by $\mathrm{H}-1 / \mathrm{N}-15$ NMR spectroscopy. Appl Microbiol Biot 77:427-436

Huang YM, Hu WW, Rustandi E, Chang K, Yusuf-Makagiansar H, Ryll T (2010) Maximizing productivity of $\mathrm{CHO}$ cell-based fed-batch culture using chemically defined media conditions and typical manufacturing equipment. Biotechnol Prog 26:1400-1410

Jain E, Kumar A (2008) Upstream processes in antibody production: evaluation of critical parameters. Biotechnol Adv 26:46-72

Kobayashi H, Motoyoshi N, Itagaki T, Suzuki M, Inokuchi N (2015) Effect of the replacement of aspartic acid/glutamic acid residues with asparagine/ glutamine residues in RNase He1 from Hericium erinaceus on inhibition of human leukemia cell line proliferation. Biosci Biotech Bioch 79:211-217 
Lu F, Toh PC, Burnett I, Li F, Hudson T, Amanullah A, Li JC (2013) Automated dynamic fed-batch process and media optimization for high productivity cell culture process development. Biotechnol Bioeng 110:191-205

Matsuoka H, Watanabe J, Takeda T (2006) Influence of both glucose and glutamine concentration on $\mathrm{mAb}$ production rate in chemostat culture of $\mathrm{CHO}$ cells. Anim Cell Technol Basic Appl Asp. 14:121-125

Nyberg GB, Balcarcel RR, Follstad BD, Stephanopoulos G, Wang DIC (1999) Metabolism of peptide amino acids by Chinese hamster ovary cells grown in a complex medium. Biotechnol Bioeng 62:324-335

Ozturk S, Riley M, Palsson B (1992) Effects of ammonia and lactate on hybridoma growth, metabolism and antibody production. Biotechnol Bioeng 39:418-431

Rajendra Y, Kiseljak D, Baldi L, Hacker DL, Wurm FM (2012) Reduced glutamine concentration improves protein production in growth-arrested $\mathrm{CHO}$ DG44 and HEK-293E cells. Biotechnol Lett 34:619-626

Sengupta N, Rose ST, Morgan JA (2011) Metabolic flux analysis of CHO cell metabolism in the late non-growth phase. Biotechnol Bioeng 108:82-92

Wipf D, Ludewig U, Tegeder M, Rentsch D, Koch W, Frommer WB (2002) Conservation of amino acid transporters in fungi, plants and animals. Trends Biochem Sci 27:139-147
Wlaschin KF, Hu WS (2006) Fedbatch FB-Lnd dynamic nutrient feeding. Adv Biochem Eng Biot 101:43-74

Wurm FM (2004) Production of recombinant protein therapeutics in cultivated mammalian cells. Nat Biotechnol 22:1393-1398

Xing ZZ, Kenty B, Koyrakh I, Borys M, Pan SH, Li ZJ (2011) Optimizing amino acid composition of $\mathrm{CHO}$ cell culture media for a fusion protein production. Process Biochem 46:1423-1429

Xu P, Dai XP, Graf E, Martel R, Russell R (2014) Effects of glutamine and asparagine on recombinant antibody production using $\mathrm{CHO}-\mathrm{GS}$ cell lines. Biotechnol Prog 30:1457-1468

Young JD (2013) Metabolic flux rewiring in mammalian cell cultures. Curr Opin Biotech 24:1108-1115

Zhao L, Fan L, Wang JQ, Niu HX, Tan WS (2009) Responses of GS-NS0 myeloma cells to osmolality: cell growth, intracellular mass metabolism, energy metabolism, and antibody production. Biotechnol Bioproc E 14:625-632

\section{Submit your manuscript to a SpringerOpen ${ }^{\circ}$ journal and benefit from:}

- Convenient online submission

- Rigorous peer review

- Immediate publication on acceptance

- Open access: articles freely available online

- High visibility within the field

- Retaining the copyright to your article

Submit your next manuscript at $>$ springeropen.com 